\title{
Classroom Flipping and Online Teaching Tool Usage Advice
}

\author{
Craig McBride \\ Wingate University
}

\begin{abstract}
A description of my experiences flipping undergraduate math and statistics courses for the first two years with advice for any fellow novice flippers. This paper discusses ways to start small and build up to a completely flipped class over the span of a few terms with advice on what technology to use including software and hardware. Students' academic performances as well as attitudinal data were collected and analyzed to see if flipping had a positive effect on learning and attitudes. Both performance and attitudes improved with flipping.
\end{abstract}

\section{Introduction}

It has been a little over two year since I tried flipping my first class, and if you are anything like I was before I began, you are both intrigued and reluctant. Intrigued because you have heard several accounts of how well flipping math and stats classes can work, but reluctant because you don't have the time to spend creating all the videos and other materials necessary to try it in your own classes. I agree that the idea of prepping your classes all over again from the ground up and creating all new materials and videos sounds daunting, but what you may not already know is that it isn't necessary. If you are passionate about teaching, and you want to see your students perform better, then flipping the classroom is for you, and I can provide you with some advice on how to avoid the mistakes I have made.

First, don't be afraid to start small. You don't have to do it all at once. Start by flipping just one chapter or even one lesson topic and then expand from there. Flipping doesn't have to include videos, and you can always use videos made by other people until you are ready to make your own. I started small with just PowerPoints and then expanded from there, and I will share my experiences with you so you don't have to reinvent the wheel. Educational fads come and go, but this is one bandwagon you WANT to jump on because the differences you will see in your students' attitudes and achievement will exceed all expectations.

\section{My journey begins}

My reasoning behind trying the experiment of "flipping" my classes was to achieve four things. Firstly, I was hoping to cover more material.
Secondly, I was hoping to engage the students more in class by "lecturing" less. Thirdly, I was hoping the students would have an enjoyable experience with math since the clear majority was non-math/science majors and most had preconceived prejudices against math. Lastly, I was hoping their grades and pass rates would increase. I had read articles and heard speakers at conferences extoll the virtues of flipping classrooms and how much success they had seen from their trials. I always wanted to try it, but I just didn't have the time to create all the videos and other materials that were (in my opinion) necessary to successfully flip a mathematics classroom, so I decided to start slowly and see what worked.

My adventures with flipping began informally in the spring of 2013 while teaching at a small private liberal arts college in the Pacific Northwest area of the United States. It was during the fall semester that I began to consider flipping on a small scale. The current (more traditional) mode of instruction just wasn't working well. The students were doing adequately well with the material, but it felt so lifeless. I had to spend most of each 50-minute class period lecturing about material while students frantically took notes or just zoned out altogether. I would elicit laughs when I could and pry answers out of them as often as possible, but they never seemed fully engaged with the material. So, over the winter break, I decide to take the plunge!

Wanting to try flipping but not having time to create videos, I decided to start with PowerPoints and some other online materials instead. The book I was using for my introductory statistics class came with a set of lecture PowerPoints created by the author/publisher. They were very thorough and covered all the information from each chapter including most or all the worked-out examples. I could augment and edit the slides relatively easily, and within a few days I had a full set of very professional looking lecture slides.

That first try at flipping was an exciting experience. I was both scared and excited at the prospect of trying something new, and having to reevaluate everything I did in and out of the classroom raised my passion for teaching to a new level. I was excited and energized, and I think the students picked up on it. 


\subsection{Initial class format}

The class was flipped from the beginning of the term utilizing PowerPoints as the major mode of delivery for lecture material and supplemented with applets, online resources, and video lessons and tutorials whenever possible. Most resources (including videos) were linked to the book or found on the internet rather than having to be created by me. Students were expected to read through the PowerPoints on their own or in groups outside of class, and classes met 4 days per week (Mon, Tue, Thu, Fri) for 50 minutes each day over a 16-week semester. Class time was devoted to answering some guided questions, homework questions, and working through examples of the techniques discussed in the PowerPoints in groups using real world data. Additionally, I would use class time to present "mini-lectures" (10-20 minutes) whenever the subject matter required it.

A typical class consisted of five minutes asking probing questions about the out-of-class material to gauge if they "got it" or not, always being prepared to lecture on every topic if needed. Then, we would spend five to ten minutes doing a few examples (1020 if it seemed like the group didn't "get it" from the slides etc.) The remaining 30 minutes was spent working in groups on more examples - slightly less if a "mini-lecture" was needed. This allowed me time each day to move around the room utilizing differentiated teaching while working with students and groups one-on-one answering questions and providing personalized formative feedback.

I was then able to use probing questions to get students to describe their thought processes and statistical reasoning skills. By requiring them to continuously "explain" their results verbally in class, they were forced to understand their results rather than just being able to get a number from a calculator. Quiz and test questions also required students to "explain and interpret" their results using complete sentences, so everything built on the verbal explanations they practiced in class. Group work was given almost every day and it usually consisted of a few questions that modeled the material being discussed with current real-world data and contexts. The flipping experiment was going so well that I decided to try adding another element halfway through the semester.

\subsection{Introduction of the online tools}

Just prior to the midterm, I introduced students to the publisher's online learning tool MyStatsLab. Since this was a "pilot program" idea, I could get free access codes (normally around $\$ 100$ each) for my students from my textbook representative. Setting up the Learning Management System (LMS) took about the same time as the PowerPoint slides.
Pearson's MyStatsLab was still new to me, but a few days of watching some YouTube videos and reading through the FAQs, and I could create a serviceable course shell with homework and quizzes for every section. Some books even come with "ready to go" course shells with all the homework assignments, quizzes, and tests already created for you! Even if you must build one from scratch, the interface is easy and you will pick it up quickly.

Students were asked to try doing the rest of their homework and quizzes for the remainder of the term online. Since the use of the LMS was not in my syllabus, I did not feel it was appropriate to force this change on them, so I made use of the LMS voluntary, and nine of the 39 students opted to continue working out of the book for homework and quizzes. The last five chapters covered (8-12) were done online, and the midway split allowed me to analyze the effectiveness of the LMS by comparing scores before and after implementation along with the 9 who opted out acting as a control group.

\section{Analyzing the impact of the LMS}

My first foray into the world of flipping allowed me to look at the effectiveness of flipping a college level introductory statistics course. Additionally, I wanted to determine if the use of the LMS had a measurable effect, so I looked at scores on their final exams, exam 3 (the only exam after implementation of the LMS), post-implementation quizzes, and final course grades. The sample consisted of $(\mathrm{N}=39)$ mostly freshman and sophomore students.

The first data I analyzed were their total course grades. Table 1 shows the breakdown of letter grades and overall course averages for all three groups. Preliminary examination of the three group means shows very little difference, and a one-way ANOVA confirmed that there was no significant difference in the three means $(F=3.26, p=0.74)$. Next I ran a chi-square analysis of the distribution of letter grades to see if they differed by group. This result also indicated no difference $\left(\chi^{2}=2.60, \mathrm{p}=0.63\right)$. Over $20 \%$ of the cells have expected counts less than 5 , so the result is suspect, but observation of the relative frequencies shows very little difference in the A and B grades.

Table 1. Course grades for all three groups

\begin{tabular}{cccccc}
\hline Group & N & Mean & A's & B's & C's \\
\hline All & 22 & 88.44 & $13(59 \%)$ & $6(27 \%)$ & $3(14 \%)$ \\
None & 9 & 88.78 & $6(67 \%)$ & $3(33 \% 0$ & 0 \\
Some & 8 & 90.73 & $5(63 \%)$ & $3(38 \%)$ & 0 \\
\hline
\end{tabular}

Results were similar when comparing the final exam grades $(\mathrm{F}=0.31, \mathrm{p}=0.73)$ and the distribution of letter grades $\left(\chi^{2}=4.96, \mathrm{p}=0.29\right)$ for the three groups. The grades $(\mathrm{F}=0.31, \mathrm{p}=0.73)$ and the 
distribution of letter grades $\left(\chi^{2}=4.96, \mathrm{p}=0.29\right)$ for exam 3 also showed no significant difference.

The average score $(\mathrm{F}=0.19, \mathrm{p}=0.83)$ and distribution of letter grades $\left(\chi^{2}=6.29, \mathrm{p}=0.18\right)$ on the four quizzes that were taken after the introduction of the online tools showed slightly more parity. However, none of the scores or distribution of letter grades differed significantly across the three groups.

This, in my opinion, is a good thing. If there was a significant improvement in online quiz scores, it would support the theory that students cheat more with online tests. If they had performed worse on the in-class exams and the course in general, it would imply that they didn't learn as well with the use of the LMS. By having similar results, it means we are free to use an LMS as a learning tool without fear that it will either hinder learning or artificially inflate scores.

\subsection{Benefits of the LMS}

If the LMS does not appear to have any effect on student performance, then why should we use them? Well, in my opinion, there are two major reasons why using the LMS is still beneficial. Firstly, it frees up valuable class time. Secondly, and most importantly in my opinion, it provides students with immediate formative feedback while allowing them to easily practice skills.

The amount of time spent in class collecting homework and handing it back was eliminated completely. That may seem small, but it adds up. Also, the students had fewer homework questions. Thus, I didn't have to dedicate as much time in class to answering them. Quizzes are graded for you, so you have more time to spend developing lesson plans and fun activities for class. Since students can review their own quizzes, I no longer needed to devote class time to going over the answers.

The students are encouraged to review their own quizzes to see what they did incorrectly and alert me if they feel they deserve more points. One of the major complaints from students is that the system can be a little too strict in how it grades things. It would mark the response " 0.5 " incorrect because it asked for the answer to be a fraction or " 1.25 " incorrect because it wanted it rounded to one decimal place. This issue led to lots of frustration and dissatisfaction initially with the quizzes. However, I found it to be an advantage because it motivated students to review all their incorrect answers looking for those that were marked incorrectly and deserved more points. This allowed them to learn from their own mistakes far more effectively than just having an answer key because they can then practice similar questions in their homework section. Each question on the quiz or test has an item number in the top right corner which identifies which homework question it is. This allows the student to then return to the homework assignment and re-do the ones they missed. The system will continue to generate new sets of data or different numbers for a question, so they can practice questions until they feel they have mastered the concept.

The biggest benefit of the LMS is that it allows students to practice homework questions repeatedly getting instant formative feedback on their work. Not only does it tell them they got an answer incorrect, but it is also intelligent enough to offer tailored advice as to what they might be doing wrong. As an educator, I feel this feedback is invaluable and logistically impossible in a paper and pencil homework situation. By doing the online work, students could practice the mechanics of getting the correct answer as many times as they felt was necessary outside of class either alone or in groups (doing homework together was encouraged), while class time could be better utilized repairing misconceptions and learning how to interpret their results and thus develop deeper understanding.

\section{Initial student attitudes}

The quantitative data showed no difference in quiz scores, test scores or final course grades for those students who used the LMS. However, the qualitative data showed a significant improvement in student attitudes. Although some students did not like the experience, most stated they enjoyed the experience during both informal and formal surveys. I collected anonymous survey responses both during and after the term. These results along with unsolicited responses both verbally and via email suggest that most students enjoyed the class and many of the non-science majors stated learning more and enjoying the class more than any other math class. When asked how they felt the flipped format compared to the more traditional lecture style format on the end of term anonymous survey, one of my more eloquent students commented thusly:

I firmly believe that class time is poorly spent learning new material. To do so would be to degrade a highly skilled professor to nothing more than an interactive text book and-even more importantly- to ignore the contribution that fellow students can have on an individual's learning. Rather, the "flipped" class allowed students who struggled with the material to come to class ready to advance their understanding, allowed students with some grasp of the material to reinforce their understanding by participating with their classmates, and gave an opportunity for students who had mastered the material to investigate beyond the narrower constrains of the text book itself. (Anonymous) 
I couldn't have said it better myself! Because this was a new experience for both me and my students, I would regularly gauge their attitudes by asking how they were doing with everything.

Flipping allowed me to cover far more material than my colleagues and I worried that the pace was too fast for the students. I covered four chapters more than I had the previous term, and while other classes stopped at simple linear regression, we continued and covered multiple regression, nonlinear regression, logistic regression, chi square goodness-of-fit, chi square contingency tables, one way ANOVA, and two-way ANOVA.

I was concerned that we might be going too fast, so I asked for their opinions on the pace of the course both before introducing the online component at the midterm (PRE) and at the end of the course (POST). The survey question was: Please rate the pace of the class from 1 to 5 ( 1 = way too slow, $2=$ kind of too slow, $3=$ just right, $4=$ kind of too fast, $5=$ way too fast) - You can use decimals etc. Figure 1 displays the results of both surveys. 23 students answered the midterm survey with a mean response of 3.43 , while 20 students responded to the end of course survey with a mean response of 3.08. The data shows the proportion of students who thought we were going too fast fell substantially.

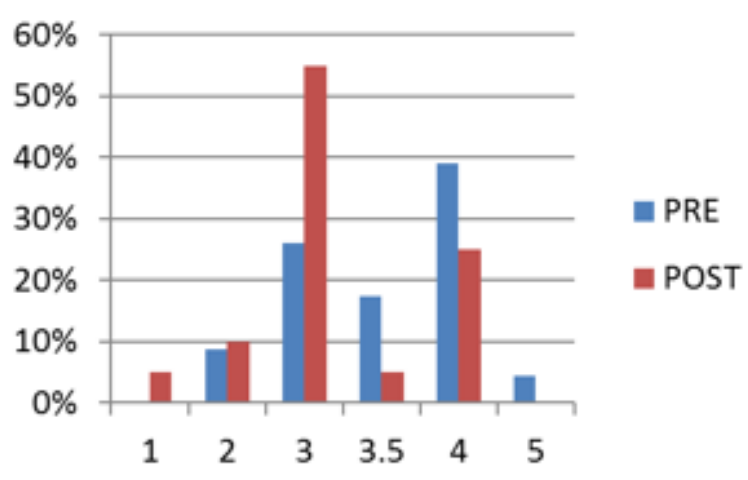

Figure 1. Student response rates

After introducing the online tools, the proportion of students who felt the pace was "just right" went from $26 \%$ to $55 \%$ while those who felt the pace was too fast (answered 4 or 5) fell from $43 \%$ to $25 \%$. This may be attributed more to the students becoming more comfortable with the flipped format, but regardless of the cause, the survey results along with my own informal surveying of asking for students' opinions during class and in office hours suggests that most students felt the pace was okay. I even had some students come into class midterm saying that friends of theirs in other classes were several weeks behind us in the material. I asked if they felt we were going too fast, and they all said "no" and they were more surprised at how "slow" the other classes were going!

\section{Phase two - other peoples' videos}

After successfully flipping my first undergraduate math class, I decided to try it again in a completely different setting to see if it could still be successful. The next fall, I began teaching at a large state university satellite campus that caters to nontraditional students. Classes typically met twice a week for 125 minutes each day during a ten-week quarter term. My first assignment was two back-toback calculus 1 classes, and just the thought of having to actually 'lecture' for nearly 4 hours straight each day made my throat hurt.

During the successful trials of the previous year, I purchased a Wacom tablet, a high-quality USB headset microphone, and Camtasia recording software. I started small by merely posting video solutions to homework questions and then graduated to making short instructional videos for some of the more confusing subjects in the statistics class. However, time constraints did not allow me to create videos for my calculus class so I had to rely on other resources.

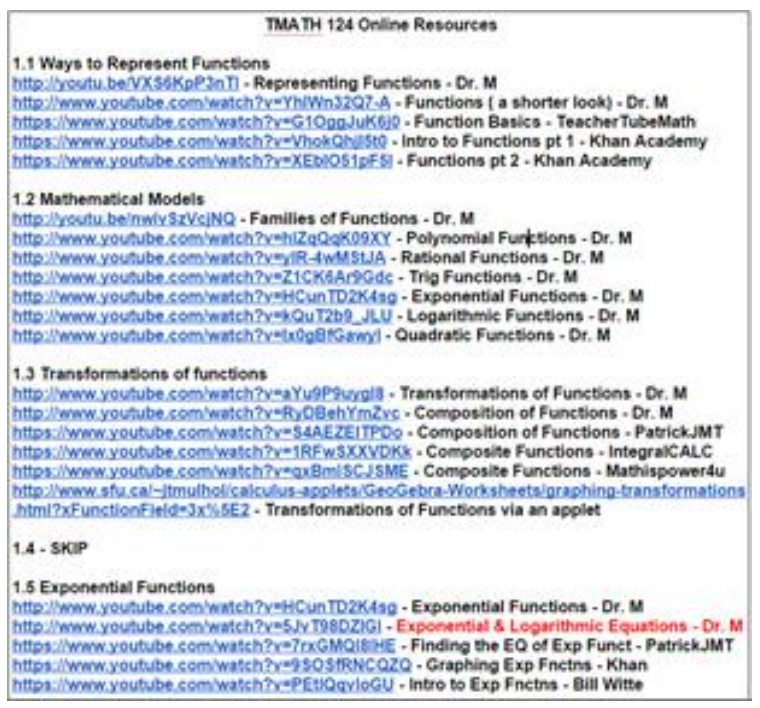

Figure 2. Sample of video links given to students

This time, I had no PowerPoints and no videos of my own, so I turned to YouTube for help. I found so many excellent videos on every subject we were going to cover that I could compile a list of five to eight video recommendations for every single chapter. I created (Figure 2) a simple Google document with the title of each chapter and hyperlinks to each video with the title and author listed. I tried to find different authors for each topic while using videos from the same people repeatedly when they turned out to be particularly good teachers. By listing the author's name for each video and offering multiple video choices for each topic, 
students could watch videos presented by the people they tended to like the best.

I modeled my overall class structure after the statistics class with more time allocated to each class phase (homework questions, group work, etc.) Students were expected to watch at least one video and begin working on their homework BEFORE class each day.

\subsection{Updated class structure}

We began each day with around 30 minutes of answering homework questions and discussing the major topics of the section. They would then take their daily Concept Check (CC) on the material. Each CC contained two to five questions taken directly from the homework, and they were intended to highlight the major topics and techniques of each section covered. Students could use their books and notes on the CCs, so care was taken to make sure that each question was not part of their actual homework assignment nor was it any odd numbered questions without first changing numbers and details. Students were given roughly 30 minutes to finish each $\mathrm{CC}$ and they brought their answers to me as they finished so I could quickly grade each one and offer instant formative assessment and feedback.

If it appeared that a majority were struggling with the same question, we would discuss as a class that question and a few similar examples after the CCs were all done. The last 30-45 minutes was spent working on homework or a worksheet of sample questions in groups or on their own. Homework and quizzes were done online using a different LMS (WebAssign) while all exams were given in class on paper.

Although I did not have any control group or experience teaching the course the "traditional" way in this new setting, I could compare my student's results with other sections of calculus 1 offered at the same school over the past few years. My pass rate was higher, and the overall average grade was also higher. Additionally, student attitudes seemed better than what my colleagues reported in their traditional classes. End of term student evaluations revealed that most favored the new format, and my classes for the next term quickly amassed long wait lists.

\section{Fully flipped with my own videos}

With the time afforded me over the winter break, I could take flipping to the next level with my next three classes. In the winter term, I had two sections of introductory statistics and one section of precalculus. Along with calculus 1, these were the three worst courses in our department in terms of non-pass rates.

\subsection{Historically low pass rates}

Precalculus was particularly bad with drop/fail rates routinely at $20-35 \%$ and sometimes as high as $50 \%$ ! The main problem with all three courses (and particularly precalculus) was the sheer volume of material that needed to be covered in such a short amount of time. It was bad enough that we were already short-changed by being on a quarter system and only meeting for 10 weeks instead of the standard 15-16 weeks that most semester schools have. However, on top of that, classes that routinely met 5 times per week for 50 minutes each day at other schools were now being taught only two days each week for 125 minutes each day! Having to cover the same amount of material meant having to cover two sections every day!

Our campus caters to non-traditional and foreign exchange students, so most are older than the usual college-aged student, they normally work full time or are in the military, and their educational backgrounds are more diverse than anything I have ever seen before in any other school. The range of math abilities in a precalculus class can span everything from those who can't add fractions to those who are basically ready for calculus already, with most on the lower end of the scale. Lecturing to these types of students for two hours and trying to get through so much material in a short amount of time just doesn't work and it was no wonder that nearly a third would drop or fail ever term.

\subsection{Flipping to the rescue!}

My previous (limited) experience with flipping taught me that it was possible to cover more material in less time, so it seemed like it would be a perfect fit for this academic setting. Since I already had so many statistics materials from my previous school, I could start creating more videos for both statistics and precalculus.

By now, I had gotten good at creating lecture videos using Camtasia, PowerPoint, a Wacom tablet and pen, and various online tools. Texas Instruments provides a free TI-83 graphing calculator emulator, so I can bring it up on the screen and show students how to input the data and conduct the necessary analyses using their calculators as I talk about various topics. Additionally, there are online statistical tools such as StatCrunch that allow students to perform fairly robust analyses with ease, which allows us more time to discuss the results and how to interpret them correctly. Since Camtasia records everything on your screen, you can use any online tools you want and the students can see how to use them as well.

Luckily for me, the precalculus book came with a great set of PowerPoint slides that I could edit and augment easily as I had done so with the original 
statistics slides. By keeping my original statistics lectures organized by topic rather than by section or chapter, I could re-use everything even with a completely different textbook. That little tip alone saves me the time and hassle of having to re-record everything whenever I change textbooks. With most of the statistics work done already, I could devote enough time to completing my entire library of statistics videos while building from scratch a set of precalculus videos.

One of the nice features of Camtasia is how seamlessly it integrates with YouTube. I can edit and then upload my videos directly to my own YouTube channel where my students (and anyone else) can watch them. Rather than requiring my students to hunt around through hundreds of videos on my channel, I create (Figure 3) simple Google docs with hyperlinks to each video placed in a schedule that I then publish to Canvas where my students can click through to my videos directly from our Canvas class site.

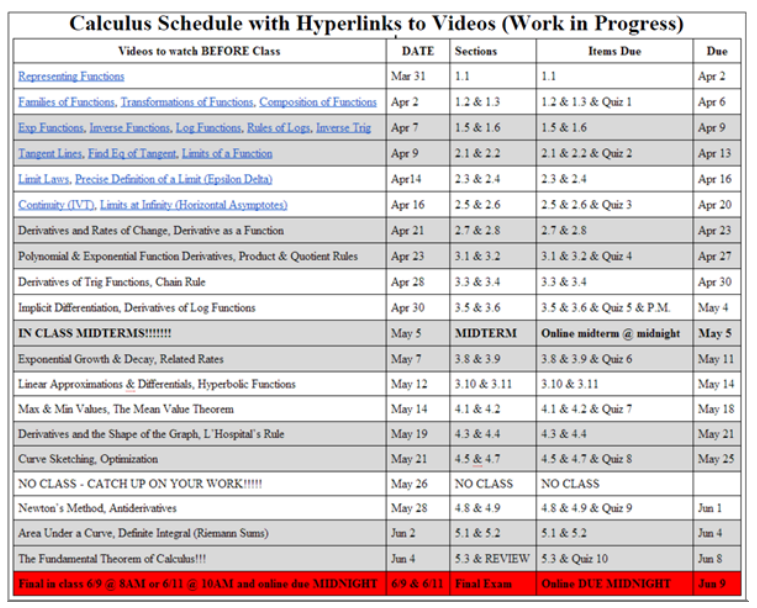

Figure 3. My (work in progress) schedule

Using Google docs allows me to make edits and changes to the "live" document without having to worry about updating it on Canvas since the file is embedded and thus gets updated similar to how a webpage is updated and yet we still get to it through the same URL address. Since my videos were a "work in progress" as the term progressed, this autoupdating feature was essential. As long as I stayed a week or two ahead of my students, I could take my time and create good videos for lectures and sample problems with solutions. I could then paste the new links in the Google doc as we went along through the term. The new links would appear on the document in Canvas and the students would continue working through the material. It also allowed me the time to answer homework questions by posting a quick video solution rather than trying to type out a solution over email, which we all know is VERY difficult with math symbols and exponents etc!
By the end of the winter term (only my third term trying any form of flipping), flipping had become easy. The students were used to the format and I could crank out videos quickly and easily. Each day before class, I would log into the LMS to see how they were doing on their homework and it was so shocking to see how many students had regularly done most if not ALL of their homework before we had even begun to discuss it in class. The students loved the format, and they were thriving in this setting.

At the end of the term, only 4 of 60 precalculus students failed mainly because all 4 had just stopped coming to class or doing any work. All 30 of the statistics students passed, and the class averages for all three were significantly better than the other sections. I began to worry that maybe I was making it too easy to get a good grade in my class because these kinds of results seemed way too good to be true. Currently, we are in the process of tracking my students to see how they perform in subsequent courses. We have data going back for several years on all students in our math classes and we hope to analyze the data in the near future to see if these students continue to perform well in other classes or not. Although I did not have time to administer my own set of surveys, student evaluations showed that once again the students liked the flipping model and word was quickly spreading around campus.

\section{Student response has been amazing!}

Last spring, I taught two sections of calculus 1 and one section of precalculus. I was supposed to only teach two classes, but after more than 38 students had requested to be waitlisted in my first section of calculus, we had to offer the second section. The courses went well and the student attitudes seemed to be so much better than in other classes. I continue to elicit feedback from my students via anonymous online surveys and the university-conducted student evaluations, and the responses are predominantly very positive.

\subsection{Student evaluation comments}

The university conducts official student evaluations at the end of each class. One question asks students what aspects of the class contributed most to their learning. The videos were popular. "The online lecture videos [were] very helpful. Being able to rewind and pause [while] I take notes" - Stats Winter2014. "The videos the instructor made [were] very helpful and whenever I was confused about a problem, I could refer back to that video for help" - Stats Winter 2014. "The videos are great. If I have trouble I can re-watch over and over." - Calc Spring2014. Comments like these show up on every evaluation summary report. 
In addition to the videos, many students think the online homework system contributed to their learning. "MyMathLab for homework and the ability to ask questions and see examples in class" - Precalc Winter2014. "The 'View an Example' button on The Pearson website is a BIG help for me" - Precalc Winter2014. "Homework helped me the most because if $I$ had a question it could be answered right away" - Calc Spring2014. "The online homework was very helpful, being able to repeat a question until it is correct definitely helped my grade" - Calc Spring2014. "The best part was unlimited attempts at online homework. Without the stress of getting the answer right or losing points, I could focus on the actual concepts and I learned a lot more than I ever did" - Precalc Summer2014. It should be noted that the calculus classes use the WebAssign online system from a different publisher, and the response is equally positive.

Many students feel the overall structure of the course and the flipping in general contributes most to their learning. "The PowerPoints were helpful, and I don't think it would have been easy to understand the concepts in class without reading them, but I definitely don't think it would have been easy to understand the PowerPoints without class time" Calc Fall2013. "The flipped method of teaching. I always had teacher help/examples online in his videos and I had class time to ask him questions for homework. It was the best use of time and most effective way I have ever been taught math" Precalc Winter2014. "The in-class lectures after watching the videos before class really helps drive home points that I may have missed previously" - Precalc Winter2014. "I like the flipped classroom idea because it allows everyone to go at their own pace and come in the day of class with questions that they may have" - Stats Winter2014.

When asked if they felt the class was intellectually stimulating, I got two of my favorite responses of all time. "Yes. He did the impossible. He made me like math. It's awesome" - Precalc Winter2014.

Very. EVERY day of this course, I found myself mentally exhausted by the time I left this class. Prof. McBride is such an intelligent, engaging instructor that his lessons absolutely locked on to my attention forcing my brain to attempt to keep pace with his. There was no "white space" through the quarter and from the time I took my seat until the time I packed up to leave, my mind was fully engaged with the subject material. I can't say that about any other course in my three years at UWT - Precalc Spring2014

These are the types of comments that can keep you going! Flipping seems to elicit these types of comments from more students, and their evaluation scores are high as well.

\subsection{Student evaluation scores}

In addition to getting mostly wonderful feedback, I was also getting exceptionally high marks on the student evaluations. A total of 187 students from nine different courses over the last year and a half completed the evaluations. Among other questions, students were asked to rate the course as a whole (4.73), the course content (4.64), and the relevance and usefulness of the course content (4.64) on a 5point scale from excellent (5) to very poor (0). In reference to the course as a whole, $67.36 \%$ ranked the courses as excellent, $23.52 \%$ ranked the courses as very good, $5.39 \%$ ranked the courses as good, and only $3.73 \%$ ranked the courses as fair or poor.

Of course, there are students who do not like the format or my teaching style, but they are a VERY small percentage; much smaller than in other nonflipped courses. Demand for my classes continues to grow and students regularly ask the administration what classes I am teaching next term or when I will be teaching a certain subject. I am hoping that future analyses of their performances will show that they are in fact learning the material better and thus performing better in future math and science classes.

\section{Conclusion - my advice}

Since I now have a complete set of videos and materials for my precalculus class and a list of very good videos for my calculus course, I have the time to begin creating my own set of lecture videos for calculus. Once again, I am creating PowerPoints and videos based on topics rather than book chapters so that they will remain relevant and useful regardless of textbook changes. This means that some chapters may require multiple videos while others only one. I have heard some experienced flippers say that videos need to be kept short (under 5-10 minutes), but my own experience is that students prefer less videos even if that means that each one is longer. Technology makes it so easy for them skip around in a video, and the psychological impact of seeing a list of ten videos to watch is far worse than having them watch two 30-minute videos.

My advice to anyone considering flipping their class (especially a math class) is to go for it, but don't be afraid to take baby steps. I understand firsthand how daunting it can feel to think about having to create all the videos and other supplemental materials, but you don't have to do it all at once. In fact, you don't have to do any of it yourself if you can find the appropriate materials from other people. There is no reason why we all must continuously reinvent the wheel ourselves when we can use each other's videos and resources. All of my videos are free to use and available on my YouTube channel (DrCraigMcBridePhD) as are thousands of other 
quality videos. You just need to take the time to watch them to see that they cover the correct things.

In each of my classes, I create a discussion board where students can post links to videos or resources that they find and I usually award small amounts of extra credit to anyone who finds good ones. Crowd source your videos! Your students already spend thousands of hours each year watching videos online, so let the experts help you find good ones. Look for resources from your textbook, the publisher, or other books. Most texts come with PowerPoints and other resources like links to applets etc. Most items are free to use with no copyright issues, and those that are copyright protected can either be allowed for use by the publisher if you ask or just use them as inspiration for your own items.

Wacom tablets are now under $\$ 100$, and most schools have site licenses for Camtasia, Tegrity, Panopto, or similar lecture capturing software. Jing is available free, but it only records in five minute increments. Simple tips like formatting all your slides to 13.3 " by 7.5 " (1280 x 720) makes the video fit perfectly on YouTube and most computer screens. Online learning management systems like WebAssign, MyMathLab, MyStatsLab, and others may seem expensive for your students with access codes costing anywhere from $\$ 65$ to $\$ 125$, but when you consider that they all come with a free copy of the eBook and most students are fine using it, it can end up costing them less. The online books also have the bonus of coming with multimedia embedded, so as students are reading through the chapter, they can click on an icon and launch a video or an applet that will help them investigate the concept. Many of the homework problems offer video or written solutions and tutorials as well. There are several websites with free applets and materials - just start looking!

Make sure and require attendance or give daily quizzes. I tried flipping an eight-week evening class once without having the quizzes, and as soon as the students figured out the videos were all online, they stopped coming to class. Out of 15 students only 3-4 would show up each night! Other teachers have expressed similar concerns or have seen similar problems where students end up treating the course like an online course since they can get all the materials outside of the classroom, so you must provide incentives for coming to class. They don't realize how much they learn from being in the classroom with other students asking questions and discussing the topics, so do whatever is necessary to make sure they attend class.

Flipping can seem like a lot of work up front and it is if you start from scratch and try to do it all at once, but you don't have to do that. Start slow - flip just one chapter or one topic or one lesson. Use other materials and videos and let other people do the heavy lifting for you until you feel comfortable enough making your own materials. As educators, we all know that an ideal student would read or at least skim through the chapter material PRIOR to class, so that we could just hit the highlights and then have more time to work examples and dive deeper into the material. As educators, we also know that students RARELY ever read the book (especially math books)! Flipping gets them to gain the same level of insight they would from reading the book by giving them the material in a mode they are more accustomed to using. PowerPoint slides, videos, applets, and other online tools are things they see and use every day and are thus far more willing to spend time utilizing. I have seen an amazing transformation in my students over a short period, and you too will be amazed at how much better your students do and how much more engaged they are in class.

\section{References}

[1] Berg, B.L. (2009). Qualitative Research Methods for the Social Sciences. Boston, MA: Allyn \& Bacon.

[2] Berrett, D. (2012). How 'Flipping' the Classroom Can Improve the Traditional Lecture, The Chronicle of Higher Education, Retrieved from http://chronicle.com/article /How-Flipping-the-Classroom/130857/. (Access Date: 02 March, 2017)

[3] Bransford, A.B., Brown, A.L., Cocking, R.R. (Ed.) (2000). How People Learn: Brain, Mind, Experience, and School. Washington, D.C.: National Academy Press.

[4] Donovan, M.S., \& Bransford, J.D. (2005). How Students Learn: Mathematics in the Classroom. Washington, D.C.: National Academies Press.

[5] Gredler, M.E. (2009). Learning and Instruction: Theory into Practice. Upper Saddle River, NJ: Pearson.

[6] Green, J.C. (2007). Mixed Methods in Social Inquiry. San Francisco, CA: Jossey-Bass.

[7] Hatch, J.A. (2002) Doing Qualitative Research in Education Settings. New York, NY: State University of New York Press.

[8] Jones, S.R., Torres, V., Arminio, J. (2006). Negotiating the Complexities of Qualitative Research in Higher Education: Fundamental Elements and Issues. New York, NY: Routledge Taylor \& Francis Group.

[9] McBride, C. (2015). Flipping Advice for Beginners: What I Learned Flipping Undergraduate Mathematics and Statistics Classes. PRIMUS: Problems, Resources, and Issues in Mathematics Undergraduate Studies (Oct 2015). Special Issue on Flipped Classroom: Reflections on Implementation. Vol 25, Issue 8, DOI: 10.1080 / 10511970.2015.1031300.

[10] McBride, C. (2015). Start Small and Build: How to Ease Into Flipping Your First Classes. International Journal for Cross-Disciplinary Subjects in Education (Dec 2015). Special Issue Vol 6, Issue 4, ISSN 20426364. 
International Journal for Infonomics (IJI), Volume 10, Issue 1, March 2017

[11] Teddlie, C., \& Tashakkori, A. (2009). Foundations of Mixed Methods Research: Integrating Quantitative and Qualitative Approaches in the Social and Behavioral Sciences. Thousand Oaks, CA: Sage Publications. 